Issues in Informing Science and Information Technology

\title{
What is the Place of Innovative ICT Uses in School Counseling?
}

\author{
Marilyn Campbell \\ Queensland University of Technology, Brisbane, Australia
}

\author{
ma.campbell@qut.edu.au
}

\begin{abstract}
With our ever-changing society there seems to be more pressures on young people. Recent epidemiological studies in Australia have found that adolescent mental health is an important public health problem (Sawyer et al., 2001). As many as one in five Australian children aged from 4 to 17 have significant mental health concerns (Zubrick, Silburn, Burton, \& Blair, 2000). However, only one in four young people receive professional help (Sawyer, et al., 2001). Schools in Australia provide school counselors to assist students, yet many young people do not avail themselves of this service. However, young people do seek help from telephone help-lines (in 2002 almost 1.1 million phone calls were made to Kids Help Line) and from the Internet (Kids Help Line, 2003a). Perhaps more anonymous forms of counseling, such as cybercounseling, could deliver a more effective service within a school setting. The difficulties and benefits of school based webcounseling are discussed in terms of therapeutic, ethical and legal issues, as well as technical problems and recent research outcomes.
\end{abstract}

Keywords: child and adolescent mental health, Internet, school counseling, webcounseling, cybercounseling

\section{Mental Health Issues of Young People}

Recent epidemiological surveys in Australia have found that adolescent mental health problems are so severe as to constitute an important public health problem (Sawyer et al., 2001). These results are similar to other developed countries (Kessler, McGonagle, Zhao et al., 1994), where an increasing prevalence of these problems has been found in young people (Zubrick, et al., 2000). As many as one in five Australian children aged from 4 to 17-years-old have significant mental health concerns (Zubrick, et al., 2000). Furthermore, there is a strong association between mental health problems and suicidal behavior (Graham et al., 2000). As suicide is a major cause of death among adolescents in Australia (Sawyer et al., 2001) there are many sectors in society grappling with these issues.

Although society is looking to assist these young people by traditional face-to-face counseling, there is a significant proportion of adolescents who do not seek help. Rickwood (1995) found approximately half of a sample of Australian secondary students did not seek help with their 'psy-

Material published as part of this journal, either on-line or in print, is copyrighted by Informing Science. Permission to make digital or paper copy of part or all of these works for personal or classroom use is granted without fee provided that the copies are not made or distributed for profit or commercial advantage AND that copies 1) bear this notice in full and 2) give the full citation on the first page. It is permissible to abstract these works so long as credit is given. To copy in all other cases or to republish or to post on a server or to redistribute to lists requires specific permission from the publisher at Publisher@InformingScience.org chological' problems. Adolescents with a mental health problem are even more unlikely to seek help (Carlton \& Deane, 2000; Deane, Wilson \& Ciarrochi, 2001).

As a consequence of the rapid expansion of technology other forms of assistance are becoming available. In- 
formation and communication technology (ICT) pervades almost all aspects of our lives. Personal computers and the Internet are becoming increasingly available in schools and in the homes of students (Guanipa, 2001; Martin, 2003). Children and adolescents have been quick to immerse themselves in these technologies with large numbers of young people already using the Internet to communicate with others (Rosenbaum et al., 1999). Young people are growing up with this technology, yet it may seem foreign to many adults. One group of service providers, Kids Help Line (KHL), has embraced the Internet to connect with young people with problems. KHL is an Australian organization providing telephone and online counseling services for young people. They first posted a website in 1996 and began providing counseling by email in 1999. In 2000, KHL launched their webcounselling service where a KHL counselor provides one-to-one real time contact via the Internet between 3pm and 9pm, Monday to Friday (Kids Help Line, 2003a).

In addition to KHL, those Australian adolescents who do seek help with mental health concerns, first access their local doctor and second, utilize school-based counseling services (Sawyer et al., 2001). This places school counselors in a position where they may be able to extend their services via the Internet and to use new technologies as an adjunct to the traditional methods of helping young people.

\section{History of ICT Use by School Counselors}

The rapid uptake of new technologies in the school counseling population is demonstrated by the fact that Moore in 1992, found only $30 \%$ of school counselors were using computers for counseling related tasks. However, by 1999, Owen and Weikel found that number had increased to $88 \%$. By 2003 computers and the Internet were seen by school counselors as useful resources for students for providing information, especially career information, analyzing assessments and email discussion groups (Guillot-Miller \& Partin, 2003). School counselors were also using the Internet for their own information, for professional development and keeping in touch with colleagues (Rust, 1995). This technology seems to have been embraced by some sections of this group as they can retrieve and disseminate information by email, videoconferencing, websites, online journals and newsletters. Supervision of practising school counselors has also been undertaken (McMahon, 2002; Myrick \& Sabella, 1995). In addition, some school counselors were also using the Internet to communicate effectively with diverse and troubled students (Guanipa, 2001).

Other community groups are also helping troubled children using information and communication technology. The Kansas University Medical Center's Telekidcare project links clinicians with clients in school health rooms using 128 kilobits per second (kbps) videoconferencing units (Whitten, Cook, \& Shaw, 1998). Software packages for use in adolescent substance abuse programs have also been developed as CD-ROMS (Gerler, 1995) to be used in schools.

Email allows school counselors to develop different forms of service delivery to clients. Email is easy to use, available to many students, is an attractive medium to young people and is not time restricting. Email may also facilitate the communication of difficulties or concerns that can be embarrassing or uncomfortable to discuss face-to-face (Creed, 1999). The asynchronous quality of emails provides both the client and counselor with more time for reflection thus perhaps enhancing counseling (Murphy \& Mitchell, 1998). The Amigos website maintained by a Californian university uses email to provide a referral service for school students although it does not provide counseling (Guanipa, 2001). Emails to increase young people's self-esteem have been reported by Thompson and Brown (2000) in a community mentoring program to primary school students. Email has also been used as an adjunct for life coaching with adolescents in their final year at school (Campbell \& Gardner, 2003).

However, there are many school counselors who are reluctant to fully engage with the new technology. Owen and Weikel (1999) found Arkansas school counselors were only moderately confi- 
dent in their use of computers with some authors speculating that the personality types who are attracted to school counseling are wary of technology (Myrick \& Sabella, 1995). They describe themselves as "people people" or "not technically minded." Othman (2000), in an exploratory study, indicated that school counselors were unready and unprepared to use the Internet to conduct online counseling sessions.

\section{Therapeutic Issues Using ICT}

The reluctance of school counselors to fully engage with new technology could stem from many factors. Often counselors are concerned (as are some clients) that the lack of nonverbal messages will hinder the counseling therapeutic process and will fundamentally undermine any good a counseling relationship is able to achieve. Cues of voice tone, body language, expression and eye contact that seem fundamental to the practice of traditional counseling are absent in cyber-based counseling. However, counselors are researching how to convey these emotional clues in textbased messages. Emotional bracketing and descriptive immediacy are two such techniques (Collie, Mitchell \& Murphy, 2000). Emoticons, semi-pictorial symbols for specific emotions, reactions or facial expressions, acronyms, changes in fonts and other techniques specific to online communication help increase understanding (Wright, 2002). In addition, an audiographic telecommunication system that supports counseling by speech and sharable computer drawings which can be used with standard home computers is being developed with adults (Collie, $\mathrm{Cu}$ branic, \& Long, 2002). Moreover, KHL has developed interactive visual tools to enhance their online counseling service (KHL, 2003c). These tools, developed in conjunction with Queensland University's Creative Industries Faculty, provide more ways for young people to express themselves by showing their emotions rather than limiting their exchanges to describing their feelings in words. A counselor can present to the client a set of icons or 'emoticons' (colored jewels) representing the most common emotions and a sliding scale from 1 to 10 to rate the intensity or frequency of their feelings. This gives added emotional expression to facilitate greater understanding similar to Murphy and Mitchell's (1998) emotional bracketing. Videoconferencing, of course, almost eliminates the lack of metacommunication.

Another therapeutic difficulty can be the issue of a perceived lack of control by counselors in the therapeutic relationship conducted online. As Wright (2002) argues this is because online work subverts traditional power relationships between counselors and clients. School counselors might be even more susceptible to the loss of this traditional power relationship than others because of the additional adult-child relationship already existing within the therapeutic relationship and the school. There are also training issues which would need to be addressed if school counselors were to use online counseling. There are different skills for use of asynchronous text-only communication for therapeutic communication (Collie et al., 2000).

\section{Ethical Issues Using ICT}

Another concern for school counselors is ethical issues; that is, will the students be properly cared for when engaging in online counseling? There are issues of confidentiality. For instance, is it safe to talk? Email can be intercepted and unless the website is secure, confidentiality cannot be ensured. However, messages can either be encrypted or password protected. Furthermore, it is very easy for the client to terminate counseling. However, this is a similar problem to phone counseling which could be overcome by asking the student for a phone number to call or SMS, or an address for an emergency. Additionally, because of the anonymity of the client there can be issues with informed consent if the client is a minor. There are however, professional associations which have written ethical guidelines, such as the American Psychological Association (2003), the National Board for Certified Counselors (2001) and the Australian Psychological Society (1999) which can assist school counselors. 


\section{Legal Issues Using ICT}

A further concern for school counselors is 'what if something goes wrong?' As members of a school community, school counselors have a duty of care to the students. In an emergency situation, contact may need to be made with police or ambulance or a child welfare agency. However, it may not be possible to assist an anonymous client in locating support services (Robson, 2000). For KHL in 2002 there were $4 \%$ of calls where help could not be given, as clients terminated the session without identifying themselves (Kids Help Line, 2003b). This needs to be weighed against the likelihood of the client not accessing help at all.

\section{Benefits of Online Counseling by School Counselors}

One of the main benefits that has been claimed for online counseling is the anonymity of the client. There are some research studies which address how the anonymity of Internet communications affects the quality of relationships formed online (Lea \& Spears, 1995). Anonymity may make communication through the Internet easier for young people who are socially awkward but nonetheless eager to connect to others (Wolak, Mitchell \& Finkelhor, 2002). KHL (2003d) reported that many young people say they would never have sought help if online counseling was not available. Further, it has been reported that the issues that they discuss on line are more severe and complex concerns of child abuse, suicide and mental health problems (Kids Help Line, 2003c). The students reported that deeply personal issues and difficult and sensitive topics are easier to write than talk about (Kids Help Line, 2003c). Even compared to those young people who rang KHL, those who accessed online counseling were three times more likely in 2002, to seek help for eating behaviors, mental health, suicide and emotional and behavior management, sexual assault and self image.

In addition, online counseling is less intrusive for young people who are often reluctant to seek help as they feel they might lose control of their emotions. Boys, who often fall into this category, seem to appreciate the less intrusive nature afforded online. A survey of young male callers by Kids Help Line in 2002 found that although nearly half (49\%) wanted to discuss their emotional experiences more often, they were concerned that people would react negatively and they would be judged as crazy or uncool. Additionally, they were afraid of being seen as weak and therefore concerned about being teased. Using computers may be particularly empowering for people who feel intimidated initially and adolescents who are familiar with technology and are averse to faceto-face counseling could benefit by cybercounselling (Collie et al., 2002).

There is also less stigmatism associated with online counseling, as no one knows if the student is accessing help. This is in direct contrast to most school counseling situations where students must get passes to be out of class to access the counselor. This is closely allied with the privacy online counseling affords, especially to boys who feel they might not be able to contain their emotions and embarrass themselves face-to-face. This is part of the client having more control and the leveling of power differences between counselor and client on line (Murphy \& Mitchell, 1998).

Online counseling also has the advantage of greater flexibility. Instead of students missing classes, they can access the school counselor at other times. Online counseling also means that there is a permanent record of the sessions. The records from email exchanges can be beneficial for a client to chart their progress, for counselor training, supervision and research (Oravec, 2000). From a school perspective the advantage over a national helpline is that the counselor is able to support within the student's community and offer face to face counseling if trust is built over time.

In addition, KHL cannot provide online services to all the young people who are currently trying to access them (Kids Help Line, 2003d). Feedback from online clients, while acknowledging their satisfaction with the quality of the counseling, are dissatisfied with the accessibility to the ser- 
vices and the delays in response. This is in spite of expansion by around $30 \%$ each year for the last 4 years. In 2003 alone there was an $80 \%$ increase in the number of webcounselling sessions and a 50\% increase in counseling emails. School counselors need to meet some of this demand.

School counselors do not have to limit their counseling to only online. As Harun, Sainudin \& Hamzah (2001) found in their study, while $52 \%$ of students from a private Malaysian college were willing to participate in e-counseling sessions, $42 \%$ were unsure, with the remainder totally rejecting the idea. One 17 year-old student commented to the school counselor that email contact was OK but he felt that face-to-face was also required for a 'real' relationship (Campbell \& Gardner, 2003).

\section{Research Outcomes}

To date the research on the effectiveness of online counseling is limited in scope and breadth. Research with online counseling and adolescents is even scarcer, while online counseling by school counselors is almost non-existent. Some researchers contend that as online relationships are different from face-to-face counseling relationships, no better or no worse, then comparing them is misguided (Anthony, 2000). However, more research at least confirming that online counseling does no harm is needed and that can be reliably studied by comparing the results of the same type of program or counseling conducted in both mediums.

Some research comparing the effectiveness of online counseling with face to face has shown no difference in effectiveness between the modalities. For example, Cohen and Kerr (1998) compared the impact of computer assisted and face-to-face techniques on client's level of anxiety and attitudes towards counseling and found no significant difference. A recent study linked clinicians from the Kansas Medical Centre with students in a primary school diagnosed with depression (Nelson, Barnard \& Cain, 2003). Twenty-eight children with an average age of 10 years 3 months were randomly divided into two groups. One group received 8 weekly cognitive- behavioral sessions for depression face-to-face with a therapist. The other group received the same program by videoconferencing. Both groups showed decreased symptoms. In addition, the videoconferencing participants reported a high level of satisfaction with the service. However, the rapid development of providing psychological services online is far outstripping research and evaluation. Even though technology is changing quickly, research needs to keep up with the provision of different services.

\section{Conclusion}

Schools are often notoriously slow to change. However, not only is the prevalence of mental health issues increasing in society (Mitchell, 2000), these problems appear to be affecting people at a younger age than previously (Zubrick, Silburn, Vimpani \& Williams, 1999). There would seem to be potential in adding another dimension of service provision for troubled young people in the form of providing them with different options to seek help. However, the expansion of web-based counseling to the school counselor's repertoire should be built around a well developed and coherent research program.

The research agenda should be such that when outcomes are examined there is sufficient and reliable data that takes into account the views of counselors, the students as clients and the professional associations. The research agenda should be driven by studies that generate both quantitative and qualitative data. To provide a solid evidence base there needs to be data from well designed studies using existing standardized measures of therapeutic change. There is also a need to "hear the voices" of the students, the clients. What are their concerns? What do they consider are access, confidentiality and trust issues in web-based counseling? Such data may best be obtained 
from interviews with those involved. However, good research is costly and limited funds could lead to fragmented, poorly designed and one-off studies.

Not only are there problems of funding for research, in this paper other issues have also been touched on. Anonymity in the counseling relationship is a double-edged sword. Many students prefer the anonymity that webcounseling can provide instead of being excused from class and going the school counselor's office. One of the barriers to help seeking behavior is the stigma associated with doing so. Young people have been shown to be very concerned about what others may think (Sawyer et al., 2001). Boys, especially, are concerned that people will react negatively, that they will be seen as weak and therefore teased. On the other hand, anonymous students could waste a counselor's time by being a false client or pretending to be someone else. There is also the issue on the web that the counselor could be false. However, in school communities safeguards can be put in place to minimize these problems, such as providing passwords to students and ensuring students email the counselor to make an appointment on the web at a certain time. In a school community, with known counselors, the possibility of false counselors is also slight.

Although we need to advance with care, with a good research base, to do nothing is to avoid a potentially useful tool. Young people are already accessing the Internet, changing the ways they communicate, so school counselors need to change with them. The new technologies are providing exciting possibilities to complement face-to-face counseling to provide more options for helping young people.

\section{References}

American Psychological Association. (2003). APA statement on services by telephone, teleconferencing and Internet. Retrieved 19.9.03 from http://www.apa.org/ethics/stmnt01.html

Australian Psychological Society. (1999). Considerations for psychologists providing services on the Internet. Retrieved 19.9.03 from http://www.psychology.org.au/members/ethics

Anthony, K. (2000). Counselling in cyberspace. Counselling, 11, 625-627.

Campbell, M.A., \& Gardner, S. (2003). A pilot study to assess the effects of life coaching with Year 12 students. Paper presented at the First Australian Conference on Evidenced-Based Coaching: Sydney.

Carlton, P.A., \& Deane, F.P. (2000). Impact of attitudes and suicidal ideation on adolescents' interventions to seek professional psychological help. Journal of Adolescence, 23, 35-45.

Cohen, G., \& Kerr, B. (1998). Computer-mediated counseling: An empirical study of a new mental health treatment. Computers in Human Services, 15, 13-26.

Collie, K., Cubranic, D., \& Long, B.C. (2002). Audiographic communication for distance counselling: A feasibility study. British Journal of Guidance and Counselling, 30, 269-284.

Collie, K., Mitchell, D., \& Murphy, L. (2000). E-mail counseling: Skills for maximum impact. ERIC document 20010901.

Creed, T. (1999, June). E-mail: Extending the classroom word. Advocate, 6-8.

Deane, F.P., Wilson, C.J., \& Ciarrochi, J. (2001). Suicidal ideation and help-negation: Not just hopelessness or prior help. Journal of Clinical Psychology, 57, 1-14.

Gerler, E.R. (1995). Advancing elementary and middle school counseling through computer technology. Elementary School Guidance and Counseling, 30, 8-16.

Graham, A., Reser, J., Scuderi, C., Zubrick, S., Smith, M., \& Turley, B. (2000). Suicide: An Australian Psychological Society discussion paper. Australian Psychologist, 35, 1-28.

Guanipa, C. (2001). Amigos: A bilingual Internet-based resource for school counselors. Professional School Counseling, 4, 362-366. 
Guillot-Miller, L., \& Partin, P.W. (2003) Web-based resources for legal and ethical issues in school coun seling. Professional School Counseling, 7, 52-60.

Harun, L., Sainudin, Z., \& Hamzah, R. (2001). E-counselling: The willingness to participate. Paper presented at the International Education Conference in Selangor, Malaysia.

Kessler, R.C., McGonagle, K.A., Zhao, S., et al. (1994). Lifetime and 12-month prevalence of DSM-III-R psychiatric disorders in the United States: Results from the National Comorbidity Study. Archives of General Psychiatry, 51, 8-19.

Kids Help Line (2003a). Online counselling 2002. Information Sheet no.27. Brisbane: Author.

Kids Help Line (2003b). Providing a better response to kids in 2002 \& 2003. Newsletter, April, 5-6.

Kids Help Line (2003c) Visual counselling 'tools' revolutionise online service. Newsletter, August, 1-2.

Kids Help Line (2003d). Online counselling: Responding to young people's feedback. Newsletter, November, 3-4.

Lea, M., \& Spears, R. (1995). Love at first byte? Building personal relationships over computer networks. In S. Duck (Ed.), Under-studied relationships: Off the beaten track (pp. 197-233). Thousand Oaks: Sage.

Martin, P. (2003). The Internet health care revolution. Inpsych, April, 5-6.

McMahon, M. (2002). Structured peer group supervision by email. Australian Guidance and Counselling Association Newsletter, 1, 19-21.

Mitchell, P. (2000). Valuing young lives: Evaluation of the National Youth Suicide Prevention Strategy. Australia: Australian Institute of Family Studies.

Moore, R.L. (1992). Computer applications by Arkansas school counsellors in conducting K-12 guidance and counselling programs. Dissertation Abstracts International, 52, 2824.

Murphy, L., \& Mitchell, D. (1998). When writing helps to heal: E-mail as therapy. British Journal of Guidance and Counselling, 26, 21-33.

Myrick, R.D., \& Sabella, R.A. (1995). Cyberspace: New place for counselor supervision. Elementary School Guidance and Counseling, 30, 35-45.

National Board for Certified Counselors (2001). The practice of Internet counseling. Retrieved 19.9.03 http://www.nbcc.org/ethics/webethics.htm

Nelson, E., Barnard, M., \& Cain, S. (2003). Treating childhood depression over videoconferencing. Telemedicine Journal and e-Health, 9, 49-55.

Oravec, J. (2000). Online counselling and the Internet: Perspectives for mental health care supervision and education. Journal of Mental Health, 9, 121-136.

Othman, M. (2000). The information highway and the readiness of counsellors in delivery of counselling services. In Z. Pihie, L. Harun, K. Yee et al. (Eds.), Proceedings of education and ICT in the new millennium (pp. 225-230). Serdang: Universiti Putra Malaysia.

Owen, D.W., \& Weikel, W.J. (1999). Computer utilization by school counsellors. Professional School Counseling, 2, 179-183.

Rickwood, D.J. (1995). The effectiveness of seeking help for coping with personal problems in late adolescence. Journal of Youth and Adolescence, 24, 685-703.

Robson, D. (2000). Ethical issues in Internet counselling. Counselling Psychology Quarterly, 13, 249-258.

Rosenbaum, M.D. Altman, D., Brodie, M., Flournoy, R., Blendon, R.J., \& Benson, J. (1999). Survey shows widespread enthusiasm for high technology. Retrieved 26.11.03 from http://www.npr.org/programs/specials/poll/technology 
Rust, E.B. (1995). Applications of the international counselor network for elementary and middle school counseling. Elementary School Guidance and Counseling, 30, 16-26.

Sawyer, M.G., Arney, F.M., Baghurst, P.A., Clark, J.J., Graetz, R.J. Kosky, R.J., et al. (2001). The mental health of young people in Australia: Key findings from the child and adolescent component of the national survey of mental health and well-being. Australian and New Zealand Journal of Psychiatry, 35, 806-814.

Thompson, A.L., \& Brown, L.L. (2000). A collaborative e-mail mentoring program for elementary school students. Professional School Counseling, 4, 71-75.

Whitten, P., Cook, D.J., Shaw, P., et al.(1998). Telekid care: Bringing health care into schools. Telemedicine Journal, 4, 335-343.

Wolak, J., Mitchell, K.J., \& Finkelhor, D. (2002). Close online relationships in a national sample of adolescents. Adolescence, 37, 441-456.

Wright, J. (2002). Online counselling: Learning from writing therapy. British Journal of Guidance and Counselling, 30, 285-298.

Zubrick, S.R., Silburn, P.B., Burton, P., \& Blair, E. (2000). Mental health disorders in children and young people: Scope, cause and prevention. Australian and New Zealand Journal of Psychiatry, 34, 570-578.

Zubrick, S.R., Silburn, S.R., Vimpami, G., \& Williams, A.A. (1999). Emergent demand for measurement indicators of social and family functioning. Paper presented at the National Workshop of Indicators of Social and Family Functioning, Commonwealth Department of Family and Community Services, Canberra.

\section{Biography}

Dr Marilyn Campbell is currently a lecturer at the Queensland University of Technology preparing school counselors in the Masters of Education program. Previous to this Marilyn supervised school counselors and has worked in early childhood, primary and secondary schools as a teacher, teacher-librarian and school counselor. Her main clinical and research interests are the prevention and intervention of anxiety disorders in young people 